\title{
ESTOQUE DE CARBONO EM CERRADO Sensu stricto DO DISTRITO FEDERAL ${ }^{1}$
}

\author{
Artur Orelli Paiva², Alba Valéria Rezende ${ }^{3}$ e Reginaldo Sergio Pereira ${ }^{3}$ \\ RESUMO - O objetivo do trabalho foi estimar o estoque de carbono da parte aérea (troncos, galhos e serapilheira) \\ e subterrânea (raízes e solo) da vegetação lenhosa de um cerrado sensu stricto, localizado na Fazenda Água Limpa, \\ da Universidade de Brasília, Distrito Federal. A área de estudo foi amostrada a partir de parcelas de 20 x 50m \\ alocadas sistematicamente. Em cada parcela foram inventariados todos os indivíduos lenhosos arbóreo-arbustivos, \\ vivos e mortos em pé, com no mínimo $5 \mathrm{~cm}$ de diâmetro tomado a $30 \mathrm{~cm}$ do solo. Foram realizadas também \\ coletas da biomassa de serapilheira; da biomassa de raízes (fina, média e grossa) e da densidade e teor de carbono \\ no solo. A profundidade máxima adotada para a coleta de biomassa da parte subterrânea foi de $2 \mathrm{~m}$. A maior \\ parte do carbono correspondeu ao compartimento solo $(88,7 \%)$, superando bastante as raízes $(7,3 \%)$, onde as \\ concentrações foram de 271,23 e 22,38 toneladas por hectare, respectivamente. Troncos e galhos totalizaram \\ 8,60 toneladas de carbono por hectare e a serapilheira, 3,62 toneladas de carbono por hectare.
}

Palavras-chave: Estoque de carbono, Biomassa e Cerrado sensu stricto.

\section{CARBON STOCK IN CERRADO Sensu stricto IN THE FEDERAL DISTRICT}

\begin{abstract}
The objective of this study was to estimate the carbon stock of the aerial section (stems, branches and litter) and belowground (roots and soil) of woody vegetation in a cerrado sensu stricto located on Água Limpa Farm, at University of Brasilia, Federal District, Brazil. The studied area was sampled from $20 \times 50 m$ plots, allocated systematically. In each plot, it was uplifted all the woody shrubby-arboreous individuals, being live and stand dead, with at least $5 \mathrm{~cm}$ of diameter taken at $30 \mathrm{~cm}$ from the ground level. It was also performed collections of litter biomass, roots biomass (fine, medium and thick) and density and soil carbon concentration. The maximum depth adopted for collection of belowground section was 2 meters. Most of the carbon corresponded to soil compartment (88.7\%), which was much more than the roots (7.3\%), where the concentrations were 271.23 and 22.38 tons per hectare, respectively. Stems and branches totalized 8.60 tons of carbon per hectare and litter, 3.62 tons of carbon per hectare.
\end{abstract}

Keywords:Carbon stock, Biomass and Cerrado sensu stricto.

\section{INTRODUÇÃO}

O aquecimento global do planeta tem sido um dos temas de maior discussão e repercussão no cenário da crise ambiental mundial. Os efeitos poderão atingir a humanidade de maneira prejudicial, porém diferenciada, pois mesmo que a gravidade desses impactos incida em todo o mundo, países com menos recursos e populações mais vulneráveis sofrerão mais intensamente (CHANG, 2004).
Embora as mudanças climáticas sejam processos naturais, obviamente numa escala de tempo geológico, a velocidade e a intensidade das mesmas foram vigorosamente modificadas a partir da Revolução Industrial no século XVIII, com uma mudança maciça nos modos de produção e consumo de energia. O resultado disso foi o aumento das emissões de gases de efeito estufa (GEE) para a atmosfera, em especial o dióxido de carbono. Diante de tal situação, várias

\footnotetext{
${ }^{1}$ Recebido em 09.03.2009 e aceito para publicação em 14.04.2011.

${ }^{2}$ Conservação Internacional, CI, Brasil. E-mail: <arturorelli@hotmail.com>.

${ }^{3}$ Universidade de Brasília, UNB, Brasil. E-mail: <albavr@unb.br> e <reginaldosp@unb.br>.
} 
nações se reuniram em 1997, na cidade de Kyoto, Japão, e elaboraram o tratado denominado Protocolo de Kyoto (GIBBS, 2005).

O ciclo global do carbono está muito associado aos ecossistemas tropicais que tanto emitem quanto absorvem o $\mathrm{CO}_{2}$ atmosférico. Assim, qualquer alteração nesses ecossistemas, decorrente de distúrbios naturais e antrópicos, acarretará mudanças nos fluxos de carbono para a atmosfera, em níveis que irão variar com a intensidade do distúrbio.

Segundo o International Panel on Climate Change (IPCC), cerca de 25\% das emissões globais de dióxido de carbono são oriundas de alterações no uso da terra, especificamente da derrubada de florestas (PIMM; JENKINS, 2005). Em geral, a substituição de florestas tropicais úmidas por sítios agropastoris tem sido uma das principais atividades antrópicas responsáveis pelo incremento de carbono na atmosfera, sobretudo na forma de $\mathrm{CO}_{2}$ (SALOMÃO, et al., 1998).

O Cerrado brasileiro, considerado a maior savana neotropical (CASTRO, 1996), representa uma parcela significativa dos ecossistemas tropicais do planeta e, portanto, tem um papel fundamental no ciclo global do carbono, atuando como grande assimilador e acumulador de carbono. Nas últimas décadas, a substituição de extensas áreas da cobertura original do Cerrado por outros usos, envolvendo desmatamento e queimadas, vem ocorrendo num ritmo acelerado e, certamente, todo este processo de substituição da vegetação tem contribuído para o aumento da quantidade de $\mathrm{CO}_{2}$ na atmosfera. A falta de estudos relacionados à quantificação da biomassa total no Cerrado compromete o entendimento do processo de conversão de $\mathrm{CO}_{2}$ no bioma.

Castro (1996) quantificou o carbono total ao longo do gradiente de vegetação em um Cerrado lato sensu, na Reserva Ecológica do Instituto Brasileiro de Geografia e Estatística (RECOR), DF, e encontrou valores variando de 229,50 t.ha-1 no campo sujo a 293,34 t.ha ${ }^{-1}$ no cerrado denso. O maior percentual de carbono estava concentrado no solo, seguido pela biomassa de raízes e pela biomassa aérea. Tal fato evidencia uma característica bastante típica dessa vegetação quando comparada às outras formações vegetais tropicais, ou seja, alta proporção de biomassa subterrânea em relação à biomassa aérea, o que resulta num elevado quociente entre raiz e parte aérea (HARIDASAN, 2000).
No Cerrado, atenção especial deve ser dada ao cerrado sensu stricto, que representa cerca de $70 \%$ do bioma, e cuja conversão indiscriminada para outros fins pode acarretar em grandes modificações no estoque de carbono presente no ecossistema. O objetivo deste estudo foi estimar o estoque de carbono, acima e abaixo do solo, em uma área de cerrado sensu stricto localizada na Fazenda Água Limpa (FAL), pertencente à Universidade de Brasília (UnB), DF.

\section{MATERIAL E MÉTODOS}

\section{1. Área de estudo}

O estudo foi realizado em uma área de 63,56 ha de cerrado sensu stricto, situado na Fazenda Água Limpa (FAL), pertencente à Universidade de Brasília (UnB), DF. A FAL possui cerca de 4.340 ha e está dentro da Área de Proteção Ambiental Gama e Cabeça-deVeado, fazendo parte da Reserva da Biosfera do Cerrado. Localiza-se a uma altitude média de $1.100 \mathrm{~m}$, entre as

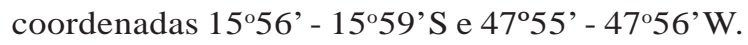

Cerca de 50\% da FAL tem sido utilizada como Estação Experimental e a outra metade compreende a Área de Relevante Interesse Ecológico Capetinga-Taquara, para fins de conservação e preservação. De acordo com Azevedo (1999), 38\% da FAL corresponde à formações de cerrado sensu stricto, classificado como cerrado típico (denso e ralo).

\subsection{Coleta de dados}

\subsubsection{Inventário da vegetação}

Para estimar o estoque de carbono do cerrado sensu stricto foram amostrados três blocos de 0,725 ha cada (145 m x 50 m), distribuídos sistematicamente na área. No processo de sistematização da amostragem, a locação do primeiro bloco se deu de forma aleatória e os dois outros blocos foram dispostos paralelamente ao primeiro, eqüidistantes em $50 \mathrm{~m}$. Cada bloco foi subdividido em seis parcelas iguais de 0,1 ha (20 m x $50 \mathrm{~m}$ ), delimitadas por estacas de ferro e separadas uma das outras por um aceiro de $250 \mathrm{~m}^{2}$ (5 m x $50 \mathrm{~m}$ ).

Em cada parcela de 0,1 ha foi realizado o inventário da vegetação lenhosa arbórea-arbustiva, considerando apenas os indivíduos vivos e mortos em pé, com diâmetro tomado a $0,30 \mathrm{~m}$ do solo (Db), igual ou superior a $5 \mathrm{~cm}$. Todos os indivíduos inventariados foram demarcados com uma etiqueta de alumínio contendo o número da 
árvore. O diâmetro dos indivíduos foi medido com suta e a altura total com uma régua hipsométrica de $15 \mathrm{~m}$. Para troncos com formato irregular, afastando-se da forma cilíndrica, o diâmetro foi medido em duas direções perpendiculares e calculada a média aritmética das medições. Para as árvores com mais de um fuste com $\mathrm{Db} \geq 5 \mathrm{~cm}$, foram registrados os valores de diâmetro (Db) e altura total $(\mathrm{H})$ de cada fuste. Cada indivíduo lenhoso foi identificado botanicamente ao nível de família, gênero e espécie.

\subsubsection{Estimativa do estoque de carbono acima do solo}

Na estimativa do estoque de carbono acima do solo foram considerados os seguintes compartimentos: tronco, galhos e serapilheira. O estoque de carbono do tronco e galhos considerou tanto árvores vivas quanto árvores mortas. Em cada parcela inventariada foi estimado o estoque para os compartimentos tronco e galhos, com base na equação alométrica desenvolvida para o mesmo cerrado sensu stricto estudado (REZENDE et al., 2006):

$$
\begin{gathered}
E C=-0,24564+0,01456 \cdot D b^{2} \cdot H\left(\mathrm{R}^{2}=98,29 \% \mathrm{e}\right. \\
\operatorname{Syx}=25,79 \%)
\end{gathered}
$$

em que: $\mathrm{EC}$ = estoque de carbono em kg por árvore; $\mathrm{Db}=$ diâmetro da base, tomado a $0,30 \mathrm{~m}$ do solo $(\mathrm{cm})$; $\mathrm{H}=$ altura total da árvore $(\mathrm{m}) ; \mathrm{R}^{2}=$ coeficiente de determinação; Syx = erro-padrão da estimativa.

Esta equação considera todos os indivíduos lenhosos com diâmetro da base, tomado a 0,30 m do solo, igual ou superior a $5 \mathrm{~cm}$. Galhos e seções com diâmetro menor que $3 \mathrm{~cm}$ são desconsiderados neste modelo. Na estimativa do estoque de carbono, este modelo considera um conteúdo de carbono correspondente a $50 \%$ da biomassa seca.

Para a estimativa do estoque de carbono na serapilheira, a coleta de dados foi realizada durante a estação seca, em meados de junho. Foi considerado como biomassa de serapilheira todo material presente na superfície do solo, tais como fragmentos de madeira, de todos os diâmetros, liteira, gramíneas e pequenas herbáceas mortas.

Para amostragem da serapilheira foram selecionadas aleatoriamente duas parcelas de 0,1 ha em cada bloco. Em cada parcela, foram escolhidos, também de forma aleatória, três locais para a amostragem da serapilheira. Em cada local foi estabelecida uma quadrícula de
0,50 m x 0,50 m e realizada a coleta de toda a serapilheira contida dentro da quadrícula. A massa verde da serapilheira contida em cada quadrícula foi obtida com o uso de uma balança de precisão 0,01 g. Em seguida, o material foi colocado em estufa com circulação forçada de ar, a $60^{\circ} \mathrm{C}$, por 72 horas, para secagem até peso constante. Após a secagem das amostras foi determinado o peso seco das mesmas e o respectivo estoque de carbono. A concentração de carbono usada para serapilheira foi de 51\% do peso seco, valor médio empregado por Castro (1996) para a biomassa de serapilheira, em áreas de cerrado sensu stricto localizadas na Reserva Ecológica do IBGE (RECOR), DF, queéuma Unidade de Conservação localizada próximo a FAL. Após obtenção do estoque de carbono por amostra de serapilheira foi feita uma extrapolação do estoque de carbono por hectare.

\subsubsection{Estimativa do estoque de carbono abaixo do solo}

Para estimar o estoque de carbono abaixo do solo foram avaliados os compartimentos raiz e solo, considerando uma profundidade máxima de até $2 \mathrm{~m}$. A coleta de dados também foi realizada durante a estação seca.

Tanto para as raízes quanto para o solo foram utilizadas as informações sobre estoque de carbono, registradas por Castro (1996), para áreas de cerrado sensu stricto localizadas na Reserva Ecológica do IBGE e na Estação Ecológica do Jardim Botânico de Brasília, DF. Essa autora estudou duas variantes de cerrado sensu stricto, cerrado aberto e cerrado denso, não verificando qualquer diferença significativa entre os totais de estoque de carbono registrados nas duas fitofisionomias. Assim, como a estrutura do cerrado sensu stricto, objeto deste estudo, se assemelha bastante ao cerrado denso estudado por Castro (1996), foram adotados os mesmos valores percentuais de estoque de carbono registrados por ela, ou seja, $87,30 \%$ do estoque de carbono estão concentrados no solo e $8,72 \%$ nas raízes.

A amostragem da biomassa de raízes visando estimar o estoque de carbono deste compartimento foi realizada em apenas uma parcela de 0,1 ha, sorteada aleatoriamente dentro de cada bloco. A escolha de apenas uma parcela foi decorrente da alta similaridade florística (0,87 a 0,91) detectada pelo índice de Sørensen (KENT; COKER, 1992) entre as parcelas dentro de cada bloco.

Em cada parcela selecionada foram demarcadas aleatoriamente quatro quadrículas de 0,50 m x 0,50 m. Em cada quadrícula foi retirado um bloco de solo de

Revista Árvore, Viçosa-MG, v.35, n.3, p.527-538, 2011 
$30 \mathrm{~cm}$ de profundidade (monolito). As raízes foram separadas da porção de solo, manualmente, e também com a ajuda de peneiras com malhas de $2 \mathrm{~mm}$, e levadas para o laboratório.

Em laboratório, todas as raízes foram separadas em três classes de diâmetro: $\leq 5$ mm (fina), 6 a 10 mm (média) e $>10 \mathrm{~mm}$ (grossa), com o auxílio de um paquímetro digital. A maior classe de diâmetro englobou também estruturas subterrâneas como xilopódios, bulbos, rizomas, tubérculos caulinares e caules subterrâneos (RODIN, 2004). Em seguida, foi obtido o peso verde de raízes por classe de diâmetro, pertencente a cada monolito, usando uma balança de precisão 0,01 g. Uma sub-amostra de cada classe de diâmetro das raízes, retirada de cada monolito, foi colocada em estufa a $60^{\circ} \mathrm{C}$, por 72 horas, até peso constante.

A biomassa de raízes a partir de $30 \mathrm{~cm}$ e até $2 \mathrm{~m}$ de profundidade foi estimada conforme as proporções observadas por Castro (1996). Segundo a autora, no cerrado lato sensu, a biomassa de raízes decresce da superfície do solo até áreas mais profundas. Grande parte das raízes concentra-se nos primeiros $30 \mathrm{~cm}$ de profundidade do solo. Para o cerrado sensu stricto denso, cerca de $71 \%$ da biomassa total de raízes estão concentrados nos primeiros $30 \mathrm{~cm}$ de profundidade do solo, $12 \%$ entre 30 e $50 \mathrm{~cm}, 13 \%$ entre 50 e $100 \mathrm{~cm}$ e $4 \%$ entre 100 e $200 \mathrm{~cm}$. A concentração de carbono considerada para as raízes foi de $48 \%$ do peso seco, valor médio registrado para raízes do cerrado sensu stricto (CASTRO, 1996).

Para efeito de amostragem do teor de carbono no solo, foram sorteadas duas parcelas de 0,1 ha em cada bloco. Em cada parcela foram selecionados aleatoriamente cinco pontos amostrais para a coleta de solo, que foi realizada com um trado em três níveis de profundidade: 0 a $10 \mathrm{~cm}, 10$ a $20 \mathrm{~cm}$ e 20 a $40 \mathrm{~cm}$. As cinco amostras de solo coletadas em cada profundidade formaram uma amostra composta, totalizando, portanto, seis amostras para cada uma das três profundidades.

Em seguida, as amostras compostas foram encaminhadas ao laboratório de solos da EMBRAPA Cerrados, Planaltina, DF. O carbono orgânico foi determinado para cada amostra pelo método WalkleyBlack (adaptado) com digestão das amostras $\left(\mathrm{H}_{2} \mathrm{SO}_{4}\right.$, 96\%) e posterior titulação de oxi-redução, com sulfato ferroso amoniacal $\mathrm{Fe}\left(\mathrm{NH}_{4}\right)_{2}\left(\mathrm{SO}_{4}\right)_{2} \cdot 6 \mathrm{H}_{2} \mathrm{O}$ a $0,5 \mathrm{~mol} / \mathrm{L}$ (EMBRAPA, 1997).

Revista Árvore, Viçosa-MG, v.35, n.3, p.527-538, 2011
Para a obtenção da densidade do solo $(\delta)$ foi sorteado dentro de cada bloco um ponto amostral, onde foram coletadas três amostras de solos, sendo uma para cada profundidade considerada: 0 a $10 \mathrm{~cm}, 10$ a $20 \mathrm{~cm}$ e 20 a $30 \mathrm{~cm}$. A coleta foi realizada com o auxílio de um cilindro de ferro com o volume previamente conhecido. Cada amostra de solo coletada foi armazenada em um recipiente de alumínio, que foi vedado e levado para o laboratório, para determinação do peso verde e do peso seco, após secagem em estufa, a $60^{\circ} \mathrm{C}$ durante 72 horas.

A partir do volume do cilindro utilizado na coleta de cada amostra de solo e do peso seco da mesma, foi calculada a densidade do solo a partir da seguinte fórmula:

$$
\delta=\frac{m}{v}
$$

em que: $\delta=$ densidade do solo $\left(\mathrm{g} / \mathrm{cm}^{3}\right) ; \mathrm{m}=$ peso seco do solo $(\mathrm{g}) ; \mathrm{v}=$ volume do cilindro $\left(\mathrm{cm}^{3}\right)$.

Como os dados referentes ao teor de carbono foram tomados nas camadas de 0 a 10, 10 a 20, e 20 a $40 \mathrm{~cm}$ de profundidade do solo e, a densidade nas camadas de 0 a 10,10 a 20 e 20 a $30 \mathrm{~cm}$, decidiu-se determinar o estoque de carbono no solo apenas de 0 a 10 e 10 a $20 \mathrm{~cm}$ de profundidade. O estoque de carbono para estas profundidades foi obtido a partir da fórmula abaixo, descrita por Szakács (2003):

$$
e=\frac{c}{100} \cdot \delta \cdot p \cdot 100
$$

em que: e = estoque de carbono (t/ha); c = teor de carbono $(\%) ; \delta=$ densidade do solo $\left(\mathrm{g} / \mathrm{cm}^{3}\right) ; \mathrm{p}=$ profundidade da camada do solo $(\mathrm{cm})$.

A partir de $20 \mathrm{~cm}$ de profundidade do solo e até a profundidade de $2 \mathrm{~m}$, foram adotadas as proporções de carbono no solo observadas por Castro (1996), que considera que $78 \%$ do carbono total do solo estão estocados entre 20 e $200 \mathrm{~cm}$ de profundidade.

\subsection{Análise dos dados}

\subsubsection{Caracterização da vegetação lenhosa arbóreo- arbustiva}

A partir dos dados do inventário foram determinados os valores absolutos e relativos de densidade e dominância (área basal), e o índice de valor de cobertura (IVC) (FELFILI; REZENDE, 2003), por espécie, visando caracterizar a cobertura arbóreo-arbustiva local. 


\subsubsection{Estimativa do estoque de carbono acima do solo}

A partir do estoque de carbono obtido para troncos e galhos dos indivíduos lenhosos arbóreo-arbustivos do cerrado estudado, foi calculado o estoque de carbono total desses componentes por espécie, bem como, o estoque médio de carbono por indivíduo dentro de cada espécie.

Os indivíduos lenhosos registrados na área de estudo foram distribuídos em classes de diâmetro e o estoque de carbono foi quantificado para cada classe, visando verificar qual classe de diâmetro concentra o maior estoque de carbono, e que fatores são responsáveis por esse estoque: espécie, densidade ou área basal. O intervalo de classe adotado neste estudo foi de $4 \mathrm{~cm}$, conforme critério adotado por Felfili e Silva-Júnior (1988) e Vale (2000) em outros estudos realizados no cerrado sensu stricto da FAL.

\subsubsection{Estimativa do estoque de carbono abaixo do solo}

O estoque de carbono para raízes finas, médias e grossas foi estimado tanto por hectare quanto para a área total do estudo. Foi realizada também uma análise de variância dos dados, considerando um delineamento inteiramente casualizado e um nível de significância de 5\%, visando verificar a ocorrência de diferenças significativas entre o estoque de carbono contido nas três diferentes classes de diâmetro. Cada classe de diâmetro de raízes foi considerada como um tratamento e cada monolito uma repetição. As médias de cada tratamento foram submetidas ao teste Tukey, ao nível de $95 \%$ de probabilidade.

A partir dos dados de teor de carbono e densidade do solo, foi possível obter os valores de estoque de carbono no solo nas camadas de 0 a $10 \mathrm{~cm}$ e 10 a $20 \mathrm{~cm}$ de profundidade. Utilizando as proporções de carbono no solo registradas por Castro (1996), foi estimado também o total de carbono estocado entre 20 cm e 200 cm de profundidade.

Os dados de estoque de carbono no solo também foram submetidos a análise de variância visando avaliar a ocorrência de diferenças significativas entre os estoques médios de carbono registrados nas diferentes camadas do solo. Considerou-se também um delineamento inteiramente casualizado e um nível de significância de 5\%; cada nível de profundidade foi considerado como um tratamento e, cada amostra composta, uma repetição. As médias de cada tratamento foram submetidas ao teste Tukey, ao nível de 95\% de probabilidade.

\section{RESULTADOS}

\subsection{Caracterização da vegetação lenhosa arbóreo- arbustiva}

No levantamento realizado foram encontrados 1.611,11 fustes arbóreos-arbustivos vivos por hectare, distribuídos em 58 espécies, 45 gêneros e 31 famílias. Além disso, cerca de 96,11 fustes.ha ${ }^{-1}$ foram encontrados mortos em pé.

A Tabela 1 mostra os valores de densidade, dominância e índice de valor de cobertura (IVC) para cada espécie registrada. As espécies mais abundantes na área foram Miconia pohliana, Ouratea hexasperma, Roupala montana, Qualea parviflora, Caryocar brasiliense, Dalbergia miscolobium, Sclerolobium paniculatum e Styrax ferrugineus. Juntas responderam por 53,44\% da densidade total de indivíduos por hectare.

A dominância total registrada na área para os indivíduos vivos foi de $10,18 \mathrm{~m}^{2}$.ha-1 e para os fustes mortos em pé, $1,17 \mathrm{~m}^{2} \cdot \mathrm{ha}^{-1}$. As espécies dominantes foram: Miconia pohliana, Ouratea hexasperma, Qualea parviflora, Caryocar brasiliense, Dalbergia miscolobium, Sclerolobium paniculatum e Vochysia thyrsoidea, que ocuparam cerca de 57,55\% da área basal total registrada no cerrado.

\subsection{Estoque de carbono acima do solo}

O estoque de carbono total para troncos e galhos, com diâmetro mínimo de $3 \mathrm{~cm}$, dos indivíduos lenhosos arbóreos-arbustivos, com $\mathrm{Db} \geq 5 \mathrm{~cm}$, no cerrado sensu stricto, foi de 8,60 t.ha-1, sendo 7,55 t.ha ${ }^{-1}$ para as árvores vivas e 1,05 t.ha-1 para as árvores mortas em pé.

A Tabela 2 apresenta uma lista das espécies com os respectivos valores de estoque total de carbono nos troncos e galhos de seus indivíduos, bem como o estoque médio por indivíduo da espécie. As espécies apresentadas na Tabela 2 referem-se apenas àquelas espécies que apresentaram no mínimo 5 fustes por hectare (41 espécies), considerando que é pequena a contribuição para o estoque de carbono total de espécies abaixo dessa densidade. Os resultados encontrados mostram que, embora a área de estudo apresente alta diversidade de espécies arbóreas, poucas espécies constituem as maiores populações e contribuem para a maior parte do carbono fixado no cerrado estudado.

Revista Árvore, Viçosa-MG, v.35, n.3, p.527-538, 2011 
Tabela 1 - Densidade absoluta (DA), densidade relativa (DR), dominância absoluta (DoA), dominância relativa (DoR) e índice de valor de cobertura (IVC) para as espécies registradas no cerrado sensu stricto da FAL/UnB, DF.

Table 1 - Absolute density $(A D)$, relative density (RD), absolute dominance (DoA), relative dominance (DoR) and covering value index (CVI) of the species registered in cerrado sensu stricto at FAL/UnB, DF.

\begin{tabular}{|c|c|c|c|c|c|}
\hline ESPÉCIE & DA (fustes.ha ${ }^{-1}$ ) & DR(\%) & $\operatorname{DoA}\left(m^{2} \cdot h^{-1}\right)$ & $\operatorname{DoR}(\%)$ & IVC(\%) \\
\hline Miconia pohliana & 217,78 & 13,52 & 1,2108 & 11,89 & 25,41 \\
\hline Sclerolobium paniculatum & 83,33 & 5,17 & 1,2183 & 11,97 & 17,14 \\
\hline Ouratea hexasperma & 120,56 & 7,48 & 0,6281 & 6,17 & 13,65 \\
\hline Qualea parviflora & 100,56 & 6,24 & 0,7383 & 7,25 & 13,49 \\
\hline Dalbergia miscolobium & 83,33 & 5,17 & 0,7906 & 7,77 & 12,94 \\
\hline Caryocar brasiliense & 83,33 & 5,17 & 0,5430 & 5,33 & 10,51 \\
\hline Vochysia thyrsoidea & 38,89 & 2,41 & 0,8070 & 7,93 & 10,34 \\
\hline Roupala montana & 105,56 & 6,55 & 0,3531 & 3,47 & 10,02 \\
\hline Styrax ferrugineus & 66,67 & 4,14 & 0,3765 & 3,70 & 7,84 \\
\hline Qualea grandiflora & 49,44 & 3,07 & 0,4615 & 4,53 & 7,60 \\
\hline Schefflera macrocarpa & 61,11 & 3,79 & 0,3692 & 3,63 & 7,42 \\
\hline Kielmeyera coriacea & 55,56 & 3,45 & 0,1632 & 1,60 & 5,05 \\
\hline Pterodon pubescens & 31,11 & 1,93 & 0,2514 & 2,47 & 4,40 \\
\hline Byrsonima pachyphylla & 44,44 & 2,76 & 0,1425 & 1,40 & 4,16 \\
\hline Palicourea rigida & 38,33 & 2,38 & 0,1739 & 1,71 & 4,09 \\
\hline Stryphnodendron adstringens & 34,44 & 2,14 & 0,1635 & 1,61 & 3,74 \\
\hline Piptocarpha rotundifolia & 36,11 & 2,24 & 0,1021 & 1,00 & 3,24 \\
\hline Vochysia elliptica & 23,33 & 1,45 & 0,1362 & 1,34 & 2,79 \\
\hline Miconia ferruginata & 25,56 & 1,59 & 0,1205 & 1,18 & 2,77 \\
\hline Erythroxylum suberosum & 30,56 & 1,90 & 0,0847 & 0,83 & 2,73 \\
\hline Eriotheca pubescens & 15,00 & 0,93 & 0,1878 & 1,84 & 2,78 \\
\hline Qualea multiflora & 21,67 & 1,34 & 0,1177 & 1,16 & 2,50 \\
\hline Aspidosperma tomentosum & 22,78 & 1,41 & 0,0753 & 0,74 & 2,15 \\
\hline Eremanthus glomerulatus & 22,22 & 1,38 & 0,0762 & 0,75 & 2,13 \\
\hline Myrsine guianensis & 20,56 & 1,28 & 0,0538 & 0,53 & 1,80 \\
\hline Erythroxylum deciduum & 17,78 & 1,10 & 0,0405 & 0,40 & 1,50 \\
\hline Erythroxylum tortuosum & 15,56 & 0,97 & 0,0474 & 0,47 & 1,43 \\
\hline Enterolobium gummiferum & 10,56 & 0,66 & 0,0776 & 0,76 & 1,42 \\
\hline Hymenaea stigonocarpa & 6,11 & 0,38 & 0,1045 & 1,03 & 1,41 \\
\hline Guapira noxia & 12,22 & 0,76 & 0,0622 & 0,61 & 1,37 \\
\hline Tabebuia ochracea & 12,78 & 0,79 & 0,0429 & 0,42 & 1,21 \\
\hline Symplocos rhamnifolia & 7,22 & 0,45 & 0,0772 & 0,76 & 1,21 \\
\hline Mimosa claussenii & 10,56 & 0,66 & 0,0364 & 0,36 & 1,01 \\
\hline Kielmeyera speciosa & 7,78 & 0,48 & 0,0424 & 0,42 & 0,90 \\
\hline Byrsonima verbascifolia & 9,44 & 0,59 & 0,0275 & 0,27 & 0,86 \\
\hline Aspidosperma macrocarpon & 7,22 & 0,45 & 0,0400 & 0,39 & 0,84 \\
\hline Blepharocalyx salicifolius & 8,33 & 0,52 & 0,0307 & 0,30 & 0,82 \\
\hline Connarus suberosus & 8,89 & 0,55 & 0,0240 & 0,24 & 0,79 \\
\hline Byrsonima coccolobifolia & 8,33 & 0,52 & 0,0237 & 0,23 & 0,75 \\
\hline Heteropterys byrsonimifolia & 6,67 & 0,41 & 0,0198 & 0,19 & 0,61 \\
\hline Pouteria ramiflora & 5,00 & 0,31 & 0,0296 & 0,29 & 0,60 \\
\hline Machaerium opacum & 4,44 & 0,28 & 0,0163 & 0,16 & 0,44 \\
\hline Banisteriopsis latifolia & 3,89 & 0,24 & 0,0164 & 0,16 & 0,40 \\
\hline Davilla elliptica & 3,89 & 0,24 & 0,0127 & 0,12 & 0,37 \\
\hline Lafoensia pacari & 3,33 & 0,21 & 0,0145 & 0,14 & 0,35 \\
\hline Miconia burchellii & 1,67 & 0,10 & 0,0154 & 0,15 & 0,25 \\
\hline Hancornia speciosa & 0,56 & 0,03 & 0,0106 & 0,10 & 0,14 \\
\hline Vochysia rufa & 1,11 & 0,07 & 0,0051 & 0,05 & 0,12 \\
\hline Dimorphandra mollis & 0,56 & 0,03 & 0,0032 & 0,03 & 0,07 \\
\hline Bowdichia virgilioides & 0,56 & 0,03 & 0,0023 & 0,02 & 0,06 \\
\hline Salacia crassifólia & 0,56 & 0,03 & 0,0021 & 0,02 & 0,06 \\
\hline Plathymenia reticulata & 0,56 & 0,03 & 0,0016 & 0,02 & 0,05 \\
\hline Guapira graciliflora & 0,56 & 0,03 & 0,0016 & 0,02 & 0,05 \\
\hline Acosmium dasycarpum & 0,56 & 0,03 & 0,0013 & 0,01 & 0,05 \\
\hline Aegiphila lhotzkiana & 0,56 & 0,03 & 0,0011 & 0,01 & 0,05 \\
\hline Brosimum gaudichaudii & 0,56 & 0,03 & 0,0011 & 0,01 & 0,05 \\
\hline Casearia sylvestris & 0,56 & 0,03 & 0,0011 & 0,01 & 0,05 \\
\hline Diospyros burchellii & 0,56 & 0,03 & 0,0011 & 0,01 & 0,05 \\
\hline TOTAL & 1611,11 & 100,00 & 10,1791 & 100,00 & 200,00 \\
\hline
\end{tabular}

Revista Árvore, Viçosa-MG, v.35, n.3, p.527-538, 2011 
Tabela 2 - Estoque de carbono (EC) total de troncos e galhos por espécie e estoque médio de carbono por indivíduo e por espécie, em toneladas por hectare, obtido no cerrado sensu stricto na FAL/UnB, DF, considerando apenas espécies com densidade mínima de 5 fustes.ha ${ }^{-1}$.

Table 2 - Total carbon stock of stems and branches per species and average carbon stock per individual and species, tons per hectare, in cerrado sensu stricto at FAL/UnB, DF, considering species with 5 trees.ha-1 minimal density.

\begin{tabular}{|c|c|c|c|}
\hline ESPÉCIE & DA(fustes.ha $a^{-1}$ ) & EC total $\left(\right.$ t.ha $\left.^{-1}\right)$ & EC $\left(\right.$ t.ha ${ }^{-1}$.fuste $\left.{ }^{-1}\right)$ \\
\hline Miconia pohliana & 217,78 & 0,7009 & 0,0032 \\
\hline Ouratea hexasperma & 120,56 & 0,1572 & 0,0013 \\
\hline Roupala Montana & 105,56 & 0,1443 & 0,0014 \\
\hline Qualea parviflora & 100,56 & 0,3928 & 0,0039 \\
\hline Sclerolobium paniculatum & 83,33 & 1,6523 & 0,0198 \\
\hline Dalbergia miscolobium & 83,33 & 0,6364 & 0,0076 \\
\hline Caryocar brasiliense & 83,33 & 0,3152 & 0,0038 \\
\hline Styrax ferrugineus & 66,67 & 0,2309 & 0,0035 \\
\hline Schefflera macrocarpa & 61,11 & 0,3129 & 0,0051 \\
\hline Kielmeyera coriacea & 55,56 & 0,0612 & 0,0011 \\
\hline Qualea grandiflora & 49,44 & 0,3365 & 0,0068 \\
\hline Byrsonima pachyphylla & 44,44 & 0,0529 & 0,0012 \\
\hline Vochysia thyrsoidea & 38,89 & 1,1415 & 0,0294 \\
\hline Palicourea rígida & 38,33 & 0,0575 & 0,0015 \\
\hline Piptocarpha rotundifolia & 36,11 & 0,0379 & 0,0010 \\
\hline Stryphnodendron adstringens & 34,44 & 0,0834 & 0,0024 \\
\hline Pterodon pubescens & 31,11 & 0,2440 & 0,0078 \\
\hline Erythroxylum suberosum & 30,56 & 0,0189 & 0,0006 \\
\hline Miconia ferruginata & 25,56 & 0,0566 & 0,0022 \\
\hline Vochysia elliptica & 23,33 & 0,1139 & 0,0049 \\
\hline Aspidosperma tomentosum & 22,78 & 0,0334 & 0,0015 \\
\hline Eremanthus glomerulatus & 22,22 & 0,0434 & 0,0020 \\
\hline Qualea multiflora & 21,67 & 0,0806 & 0,0037 \\
\hline Myrsine guianensis & 20,56 & 0,0240 & 0,0012 \\
\hline Erythroxylum deciduum & 17,78 & 0,0067 & 0,0004 \\
\hline Erythroxylum tortuosum & 15,56 & 0,0073 & 0,0005 \\
\hline Eriotheca pubescens & 15,00 & 0,1870 & 0,0125 \\
\hline Tabebuia ochracea & 12,78 & 0,0160 & 0,0013 \\
\hline Guapira noxia & 12,22 & 0,0308 & 0,0025 \\
\hline Enterolobium gummiferum & 10,56 & 0,0517 & 0,0049 \\
\hline Mimosa claussenii & 10,56 & 0,0186 & 0,0018 \\
\hline Byrsonima verbascifolia & 9,44 & 0,0094 & 0,0010 \\
\hline Connarus suberosus & 8,89 & 0,0070 & 0,0008 \\
\hline Blepharocalyx salicifolius & 8,33 & 0,0157 & 0,0019 \\
\hline Byrsonima coccolobifolia & 8,33 & 0,0110 & 0,0013 \\
\hline Kielmeyera speciosa & 7,78 & 0,0177 & 0,0023 \\
\hline Symplocos rahmnifolia & 7,22 & 0,0331 & 0,0046 \\
\hline Aspidosperma macrocarpon & 7,22 & 0,0235 & 0,0033 \\
\hline Heteropterys byrsonimifolia & 6,67 & 0,0111 & 0,0017 \\
\hline Hymenaea stigonocarpa & 6,11 & 0,0974 & 0,0159 \\
\hline \multirow[t]{2}{*}{ Pouteria ramiflora } & 5,00 & 0,0195 & 0,0039 \\
\hline & TOTAL & 1586,67 & 7,4923 \\
\hline
\end{tabular}

Na Figura 1 é ilustrado o estoque de carbono por classe de diâmetro, considerando as árvores vivas e mortas em pé. Observou-se que existe uma tendência de redução nos valores percentuais de estocagem de carbono nas árvores vivas das menores classes de diâmetro para as maiores, em função da redução na densidade de indivíduos com o aumento das classes de diâmetro.

Analisando-se o estoque de carbono nas árvores mortas em pé, verificou-se que a maior concentração de carbono encontrava-se nas classes de diâmetro 


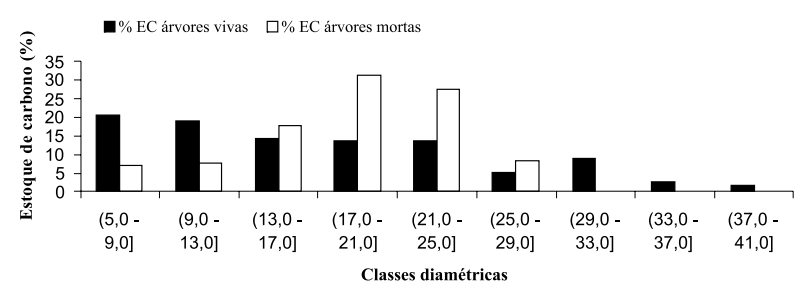

Figura 1 - Distribuição dos valores percentuais de estoque de carbono das árvores vivas e mortas em pé, em função das classes de diâmetro, em um cerrado sensu stricto na FAL/UnB, DF.

Figure 1 - Distribuição dos valores percentuais de estoque de carbono das árvores vivas e mortas em pé, em função das classes de diâmetro, em um cerrado sensu stricto da $F A L / U n B, D F$.

intermediárias, ou seja, de 13 a 17 cm até a classe de $21 \mathrm{a} 25 \mathrm{~cm}$. Isto pode ser atribuído, em parte, à alta mortalidade de indivíduos de Sclerolobium paniculatum nessa faixa de diâmetro, onde a ausência prolongada de distúrbios foi marcada até mesmo pela superação do estoque de carbono contido nas árvores mortas em pé em relação às vivas.

Os valores de biomassa presentes na serapilheira variaram de 4,54 t.ha ${ }^{-1}$ a 9,47 t.ha-1 (média de 7,11 t.ha ${ }^{-1}$ ) e o estoque de carbono de 2,32 t.ha-1 a 4,83 t.ha ${ }^{-1}$, com valor médio de 3,62 t.ha ${ }^{-1}$.

No cerrado estudado, o estoque de carbono total registrado acima do solo, considerando os compartimentos troncos, galhos e serapilheira, variou de 10,92 a 13,43 t.ha-1 .

\subsection{Estoque de carbono abaixo do solo}

O estoque de carbono nas raízes até $30 \mathrm{~cm}$ de profundidade do solo variou significativamente entre as classes de diâmetro das raízes (Tabela 3). Quando as médias foram comparadas pelo teste Tukey, verificou-se que o maior estoque foi registrado nas raízes grossas, enquanto que as raízes classificadas como médias, apresentaram os menores valores $(p \leq 0,05)$. As raízes finas contribuíram com pouco mais de um terço da biomassa total de raízes. O estoque de carbono total de raízes, até a profundidade de $2 \mathrm{~m}$ foi de 22,38 t.ha-1.

Diferenças significativas $(\mathrm{p} \leq 0,05)$ também foram detectadas pelo teste Tukey, ao se comparar o teor de carbono no solo em diferentes profundidades (Tabela 4). O maior teor de carbono $\left(3,49 \pm 0,34\right.$ t.ha $\left.{ }^{-1}\right)$ foi registrado na camada de 20 a $40 \mathrm{~cm}$ de profundidade. As camadas superiores $(0-10 \mathrm{~cm}$ e $10-20 \mathrm{~cm})$ foram estatisticamente iguais. No entanto, apesar dos teores de carbono serem estatisticamente iguais nas duas camadas, o mesmo não foi observado para o estoque de carbono nessas camadas. Na profundidade de 10 a $20 \mathrm{~cm}$ do solo foi registrado o maior estoque de carbono $(40,30 \pm 8,67$ t.ha-1 $)$, o qual se diferenciou significativamente do estoque encontrado na camada de 0 a $10 \mathrm{~cm}$ do solo $(\mathrm{p} \leq 0,05)$.

\section{DISCUSSÃO}

Em 1997, Vale (2000) inventariou o cerrado estudado e registrou 673 fustes.ha-1, pertencentes a espécies lenhosas arbóreas-arbustivas. A densidade encontrada por Vale (2000) foi cerca de $60 \%$ inferior a registrada neste estudo $(1707,22$ fustes.ha-1). O aumento na densidade de indivíduos no cerrado sensu stricto da FAL foi também observado por Libano (2004), que avaliou diferentes levantamentos realizados trienalmente em parcelas permanentes instaladas em 1983 em outra comunidade de cerrado sensu stricto na FAL. A autora registrou valores crescentes de densidade da flora lenhosa arbóreo-arbustiva local, com acréscimo de 65\% entre os anos de 1997 e 2003, além de aumento na taxa de recrutamento, e justificou esse aumento a ausência

Tabela 3 - Biomassa e estoque de carbono de raízes (t/ha) em um cerrado sensu stricto na FAL/UnB, DF. Média \pm erro padrão. Table 3 - Roots biomass and carbon stock $(t / h a)$ in a cerrado sensu stricto of FAL/UnB, DF. Mean \pm Standard error.

\begin{tabular}{|c|c|c|c|}
\hline Classe de diâmetro (mm) & Profundidade máxima (cm) & Biomassa $\left(\right.$ t.ha $\left.^{-1}\right)$ & Estoque de Carbono (t.ha-1) \\
\hline Finas $\leq 5$ & 30 & $11,19 \pm 1,99$ b & $5,37 \pm 0,95 \mathrm{~b}$ \\
\hline Médias 6 a 10 & 30 & $8,91 \pm 1,00$ & $4,28 \pm 0,48$ \\
\hline Grossas $>10$ & 30 & $13,01 \pm 2,74^{a}$ & $6,24 \pm 1,31^{a}$ \\
\hline Todas & Subtotal até 30 & $33,11 \pm 1,78$ & $15,89 \pm 0,85$ \\
\hline Todas & 30 a 200 & $13,52 *$ & $6,49^{*}$ \\
\hline Todas & Total até 200 & $46,63 *$ & $22,38 *$ \\
\hline
\end{tabular}

Letras diferentes demonstram diferenças significativas (p d” 0,05) quando testado o estoque de carbono nas três classes de diâmetro.

* Valores baseados nas proporções de biomassa de raiz descritas por Castro (1996).

Revista Árvore, Viçosa-MG, v.35, n.3, p.527-538, 2011 
Tabela 4 - Teor e estoque de carbono do solo em um cerrado sensu stricto na FAL/UnB, DF, comparado com os valores de um cerrado denso da RECOR, DF. Média \pm EP.

Table 4 - Soil carbon concentration and stock in a cerrado sensu stricto at FALI/UnB, DF, compared with values from a dense cerrado of RECOR, DF. Mean \pm Standard error.

\begin{tabular}{|c|c|c|c|c|}
\hline \multirow[t]{2}{*}{ Profundidade(cm) } & \multirow[t]{2}{*}{ Teor de Carbono (\%) } & \multirow[t]{2}{*}{ EC $\left(\right.$ t.ha $\left.a^{-1}\right)$} & \multicolumn{2}{|c|}{$\begin{array}{l}\text { Cerrado denso RECOR } \\
\text { (CASTRO, 1996) }\end{array}$} \\
\hline & & & Profundidade $(\mathrm{cm})$ & EC $\left(\right.$ t.ha $\left.^{-1}\right)$ \\
\hline 0 а 10 & $2,73 \pm 0,48^{\mathrm{b}}$ & $19,37 \pm 3,75^{b}$ & 0 a 10 & $31,99 \pm 0,86$ \\
\hline 10 a 20 & $2,55 \pm 0,50^{\mathrm{b}}$ & $40,30 \pm 8,67^{a}$ & 10 a 20 & $24,97 \pm 0,62$ \\
\hline Subtotal até 20 & - & $59,67 \pm 6,89$ & 20 a 30 & $23,05 \pm 0,57$ \\
\hline 20 a 40 & $3,49 \pm 0,34^{\mathrm{a}}$ & - & 30 a 50 & $25,20 \pm 0,66$ \\
\hline 20 a 200 & - & $211,56 *$ & 50 a 100 & $55,41 \pm 2,86$ \\
\hline Total até 200 & - & $271,23^{*}$ & 100 a 200 & $94,41 \pm 3,23$ \\
\hline
\end{tabular}

Letras diferentes demonstram diferenças significativas (p d” 0,05) quando testado o estoque de carbono nas diferentes profundidades do solo. * Valores baseados nas proporções de carbono no solo descritas por Castro (1996).

de queimadas nas áreas desde 1994. A área basal total registrada por Vale (2000) foi igual a $6,23 \mathrm{~m}^{2} \cdot \mathrm{ha}^{-1}$, ou seja, cerca de $45 \%$ menor do que a registrada neste estudo (11,35 $\left.\mathrm{m}^{2} \cdot \mathrm{ha}^{-1}\right)$. No estudo realizado por Libano (2004), foi encontrada uma área basal de $7,93 \mathrm{~m}^{2}$.ha-1 no ano de 2003 (41\% a mais que no levantamento feito em 1997) e, segundo a autora, isto pode ser explicado pela ausência prolongada do fogo, o que contribui para que a comunidade incremente sua área basal.

O estoque de carbono total (8,60 t.ha $\left.{ }^{-1}\right)$ para troncos e galhos dos indivíduos lenhosos encontra-se dentro do intervalo registrado em áreas de cerrado sensu stricto, conforme estudo realizado por Rezende e Felfili (2004). Estas autoras avaliaram o estoque de carbono nos troncos e galhos de plantas lenhosas do cerrado sensu stricto do Brasil Central, seguindo a mesma metodologia adotada neste estudo e encontraram valores que variaram de 3,71 t.ha ${ }^{-1}$ em Patrocínio (MG) a 13,27 t.ha ${ }^{-1}$ em Alvorada do Norte (GO).

Entretanto, quando comparado a estoques de carbono na Floresta Amazônica e em florestas plantadas, nota-se que o valor ébem inferior. NaAmazônia, Higuchi e Carvalho Jr. (1994), estudando uma área de aproximadamente 20 ha de floresta tropical úmida densa de terra firme, encontraram cerca de 177 t.ha $^{-1}$ de carbono na biomassa de tronco e galhos de árvores com DAP igual ou superior a $5 \mathrm{~cm}$. Nesta área, o diâmetro das árvores variava de 5 a $120 \mathrm{~cm}$ e a altura de 1,3 a $38 \mathrm{~m}$. Em povoamentos com seis anos de idade de Eucalyptus grandis em Viçosa (MG), Paixão et al. (2006) estimaram o estoque médio de carbono em 39,04 t.ha ${ }^{-1}$ para o fuste sem casca e 3,69 t.ha- ${ }^{-1}$ para os galhos.
Na área estudada, as espécies Vochysia thyrsoidea, Sclerolobium paniculatum, Hymenaea stigonocarpa, Eriotheca pubescens, Pterodon pubescens e Dalbergia miscolobium foram as que apresentaram maior estoque médio de carbono por indivíduo e juntas, contribuíram com 52,78\% do estoque de carbono total. Embora as espécies Hymenaea stigonocarpa e Eriotheca pubescens tenham apresentado baixas densidades, elas contribuíram de forma significativa para o estoque de carbono total.

Quando comparado a outros ecossistemas florestais, a biomassa de serapilheira contida no cerrado estudado foi bem inferior (média de 7,11 t.ha-1). Fearnside (1994) relata que para a Amazônia, o estoque médio de carbono na serapilheira é de 10,31 t.ha-1 , baseado em vários estudos desenvolvidos por vários pesquisadores na região. No entanto, em um povoamento de Araucaria angustifolia, com 17 anos, localizado em Pinhal Grande (RS), Schumacher et al. (2004) encontraram um valor de 6,9 t.ha $^{-1}$ para a biomassa de serapilheira, o que resultaria em valores de estoque de carbono na serapilheira comparáveis ao valor encontrado neste estudo.

O aumento da densidade da vegetação se reflete numa menor contribuição das raízes finas no cômputo da biomassa total ao longo do gradiente de vegetação do Cerrado lato sensu (CASTRO, 1996; RODIN, 2004). Rodin (2004) registrou um estoque de carbono na biomassa subterrânea do cerrado denso da RECOR em torno de 17,5 t.ha ${ }^{-1}$, assumindo que $50 \%$ da biomassa seca de raízes é composta pelo elemento carbono. A biomassa de raízes finas ( $<2 \mathrm{~mm}$ ), até $3 \mathrm{~m}$ de profundidade foi quantificada em 12,2 $\pm 0,76$ t.ha-1 e a biomassa de raízes grossas até $8 \mathrm{~m}$ de profundidade foi de 22,9 $\pm 3,14$ t.ha-1.

Revista Árvore, Viçosa-MG, v.35, n.3, p.527-538, 2011 
A heterogeneidade espacial da biomassa subterrânea, as profundidades e as classes de diâmetro estabelecidas para a coleta de raízes, a dificuldade na separação das raízes do solo, as diferenças na composição florística e na densidade da cobertura arbórea, bem como a época do ano em que é feita a coleta dos dados, podem influenciar nos resultados sobre biomassa e estoque de carbono de raízes. Mesmo assim, quando comparado a outras savanas tropicais do mundo, o cerrado sensu stricto sobressai-se quanto ao estoque de carbono presente nas raízes, mesmo considerando metodologias diferenciadas (SARMIENTO; VERA, 1979; MENAUT; CESAR, 1982). No entanto, os valores podem ser inferiores aos encontrados em florestas tropicais. Cairns et al. (1997), por exemplo, citam um total de 34,5 t.ha-1 para floresta baixa tropical no Brasil e 28,0 t.ha ${ }^{-1}$ para floresta úmida montana na Venezuela.

Considerando as proporções sugeridas por Castro (1996), verificou-se que até a profundidade de $2 \mathrm{~m}$, o cerrado estudado tem estocado no solo cerca de 271,23 t.ha-1 de carbono. Assume-se que há um estado de equilíbrio entre a quantidade fixada e liberada de carbono em ecossistemas não perturbados e, conseqüentemente, boa contribuição do carbono orgânico no solo, proveniente da decomposição de resíduos de plantas (parte aérea e raízes) (SILVA; RESCK, 1997). Nesse estudo não foi considerada e nem efetuada distinção entre camadas de solo.

Embora no cerrado sensu stricto, a biomassa acima do solo estoque quantidades bem menores de carbono do que os demais componentes do ecossistema (raízes e solos), conforme observado por Castro (1994), a sua presença é importante para a manutenção do fluxo de carbono no ecossistema.

Vários estudos sobre estoque de carbono vêm sendo realizados para a Floresta Amazônica. Klinge (1973, apud SALATI, 1994), encontrou um estoque de 380 t.ha $^{-1}$ de carbono, sendo que deste total, 185 t.ha ${ }^{-1}$ era referente a matéria viva acima do solo, que incluiu folhas, galhos e troncos. Higuchi e Carvalho (1996) avaliaram apenas o estoque de carbono acima do solo. Do total encontrado (235 t.ha ${ }^{-1}$ ), 86\% eram provenientes da matéria viva, que incluiu folhas, galhos e troncos.

As estimativas de biomassa e estoque de carbono registradas neste estudo refletem as características do cerrado sensu stricto da Fazenda Água Limpa, UnB,
DF. Diferentes ecossistemas e variações bióticas ou abióticas requerem metodologias específicas a serem aplicadas.

O valor do estoque de carbono total na área de

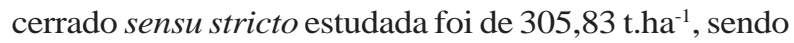
que $88 \%$ deste total corresponderam ao estoque presente no solo, $7,31 \%$ às raízes e $4 \%$ à parte aérea, formada por troncos, galhos e serapilheira. Valores entre 250 e 300 t.ha $^{-1}$ são comuns para esse tipo de fitofisionomia (REZENDE; FELFILI, 2004).

A alta concentração de carbono abaixo do solo em relação à porção acima em todos os ecossistemas do Cerrado (KAUFFMAN, et al., 1994) é uma eficiente estratégia para a conservação de nutrientes diante de distúrbios como o fogo, pois a condutividade térmica no solo é muito baixa.

A biomassa aérea presentenos ecossistemas amazônicos é superior à encontrada em ambientes savânicos. De um total de 586 t.ha $^{-1}$, cerca de 196 t.ha-1 $(33,45 \%)$ está abaixo do solo e a maior parte, 390 t.ha ${ }^{-1}$ (66,55\%), na parte aérea (KLINGE; RODRIGUES, 1973). Até mesmo os ecossistemas da Caatinga são reportados na literatura por apresentarem um conteúdo de biomassa e nutrientes maior que o do cerrado sensu stricto, com 34 t.ha ${ }^{-1}$ de carbono quantificado na biomassa da parte aérea (KAUFFMAN, et al., 1994).

\section{CONCLUSÃO}

Foi evidenciada uma supremacia do estoque de carbono contido no solo em relação aos componentes raízes e parte aérea para o cerrado sensu stricto estudado. As raízes grossas assumiram o papel principal na estocagem de carbono, superando as raízes de menor diâmetro. O carbono presente nas árvores mortas em pé representou parcela significativa do total de carbono estocada na biomassa acima do solo.

\section{REFERÊNCIAS}

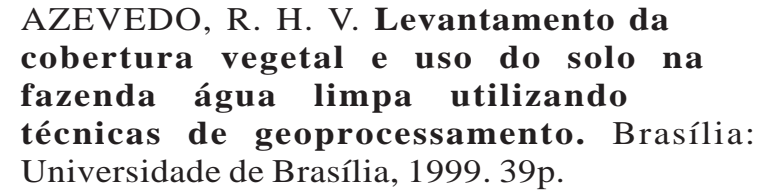

CHANG, M. Y. Seqüestro florestal de carbono no Brasil. Dimensões políticas, socioeconômicas e ecológicas. São Paulo: Annablume/IEB, 2004. 280p. 
CAIRNS, M. A. et al. Root biomass allocation in the world's upland forests. Oecologia, v.111, p.1-11, 1997.

CASTRO, E. A. Biomass, nutrient pools and response to fire in the Brazilian Cerrado. 1996. 118f. (MS Thesis) - Oregon State University, Corvallis, 1996.

\section{EMPRESA BRASILEIRA DE PESQUISA} AGROPECUÁRIA - EMBRAPA. Centro Nacional de Pesquisa de Solos. Manual de métodos de análise de solo. Rio de Janeiro: 1997. 212p.

FEARNSIDE, P. M. Biomassa das florestas amazônicas brasileiras. In: SEMINÁRIO EMISSÃO X SEQÜESTRO DE $\mathrm{CO}_{2}$ : uma nova oportunidade de negócios para o Brasil, 1994, Rio de Janeiro. Anais... Rio de Janeiro: CVRD/FBDS, 1994. p.95-124.

FELFILI, J. M.; REZENDE, R. P. Conceitos e métodos em fitossociologia. Brasília: Universidade de Brasília, Departamento de Engenharia Florestal. Comunicações Técnicas Florestais, v.5, n.1, p.1-68, 2003.

FELFILI, J. M.; SILVA-JÚNIOR, M. C. Distribuição dos diâmetros numa faixa de cerrado na Fazenda Água Limpa (FAL) em Brasília-DF. Acta

Botânica Brasílica, v.2, n.1-2, p.85-104, 1988.

GIBBS, W.W. A escolha das prioridades.

Scientific American - SCIAM, v.4, n.41, p.100-107, 2005. (Edição Especial).

HARIDASAN, M. Nutrição mineral de plantas nativas do Cerrado. Revista Brasileira de Fisiologia Vegetal, v. 12, n. 1, p. 54-64, 2000.

HIGUCHI, N.; CARVALHO JR., J. A. Fitomassa e conteúdo de carbono de espécies arbóreas da Amazônia. In: SEMINÁRIO EMISSÃO X SEQÜESTRO DE $\mathrm{CO}_{2}$ : uma nova oportunidade de negócios para o Brasil. Anais... Rio de Janeiro: CVRD/FBDS, 1994. p.125-153.

KAUFFMAN, J. B.; CUMMINGS, D. L.; WARD, D. E. Relationships of fire, biomass and nutritional dynamics along vegetation gradient in the Brazilian Cerrado. Journal of Ecology, v.82, n.3, p.519-531, 1994.

KENT, M.; COKER, P. Vegetation description and analysis. London: Belhaven Press, 1992. 363p.
KLINGE, H.; RODRIGUES, W. A. Biomass estimation in a Central Amazonian rain forest. Acta Cientifica Venezolana, v.24, p.225237, 1973.

LIBANO, A. M. Mudanças na composição florística e na fitossociologia da vegetação lenhosa de um cerrado sensu stricto na Fazenda Água Limpa (FAL) - DF, em um período de 18 anos (1985-2003). 2004. 110f. Dissertação (Mestrado em Botânica) - Universidade de Brasília, Instituto de Biologia, Departamento de Botânica, Brasília, 2004.

MENAUT, J. C.; CESAR, J. The structure and dynamics of a west African savanna. In: HUNTLEY, B. J.; WALKER, B. H. (Eds.). Ecology of tropical savannas. Berlin: Springer-Verlag, 1982. p.80-100.

PAIXÃO, F. A. et al. Quantificação do estoque de carbono e avaliação econômica de diferentes alternativas de manejo em um plantio de eucalipto. Revista Árvore, v.30, n.3, p.411-420, 2006.

PIMM, S. L.; JENKINS, C. Conservação da biodiversidade. Scientific American SCIAM, v.4, n. 41, p.58-65, 2005. (Edição Especial).

REZENDE, A. V. et al. Comparação de modelos matemáticos para estimativa do volume, biomassa e estoque de carbono da vegetação lenhosa de um cerrado sensu stricto em Brasília, DF. Scientia Forestalis, n.71, p.65-73, 2006.

REZENDE, A. V.; FELFILI, J. M. Avaliação do estoque de carbono do cerrado sensu strico do Brasil Central. Comunicações Técnicas Florestais, v.6, n.2, p.1-27, 2004.

RODIN, P. Distribuição da biomassa subterrânea e dinâmica de raízes finas em ecossistemas nativos e em uma pastagem plantada no Cerrado do Brasil Central. 2004. 88f. Dissertação (Mestrado em Ecologia) - Departamento de Ecologia, Universidade de Brasília, Brasília, 2004.

SALATI, E. Emissão X seqüestro de $\mathrm{CO}_{2}$ : uma nova oportunidade de negócios para o Brasil. Sumário Executivo. In: SEMINÁRIO EMISSÃO X

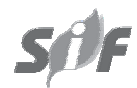

Revista Árvore, Viçosa-MG, v.35, n.3, p.527-538, 2011 
SEQÜESTRO DE CO : uma nova oportunidade de negócios para o Brasil, 1994, Rio de Janeiro. Anais... Rio de Janeiro: CVRD/FBDS, 1994. 222p.

SALOMÃO, R. P.; NEPSTAD, D.C.; VIEIRA, I.C.G. Biomassa e estoque de carbono de florestas primária e secundária. In: GASCAR, C.;

MOUTINHO, P. (Ed.). Floresta Amazônica: dinâmica, regeneração e manejo. Manaus: INPA, 1998. 373p.

SARMIENTO, G.; VERA, M. Composicion, estructura, biomassa y produccion de diferenes sabanas em los Llanos de Venezuela. Boletin de la Sociedade de Venezolana de Ciencias Naturales, v.136, p.5-41, 1979.

SCHUMACHER, M. V. et al. Produção de serapilheira em uma floresta de Araucaria angustifolia (Bertol) Kuntze no município de Pinhal Grande-RS. Revista Árvore, v.28, n.1, p.29-37, 2004.
SILVA, J. E.; RESCK, D. V. S. Matéria orgânica do solo. In: VARGAS, M.A.T.; HUNGRIA, M. (Orgs.). Biologia dos solos dos cerrados. Planaltina: Embrapa/CPAC, 1997. p.467-524.

SZAKÁCS, G. G. J. Seqüestro de carbono nos solos - avaliação das

potencialidades dos solos arenosos sob pastagens, Anhembi -

Piracicaba/SP. 2003. 126f. Dissertação (Mestrado em Ciências, Energia Nuclear na Agricultura) - Centro de Energia Nuclear na Agricultura da Universidade de São Paulo, Piracicaba, 2003.

VALE, A.T. Caracterização da biomassa lenhosa de um cerrado sensu stricto da região de Brasília para uso energético. 2000. 111f. Tese (Doutorado em Agronomia) Universidade Estadual de São Paulo, Botucatu, 2000. 